\title{
Application of the PRMS model in the Zhenjiangguan watershed in the Upper Minjiang River basin
}

\author{
LONGZHANG FANG, CHAO LIU, GUANGHUA QIN, BIN ZHANG \& \\ TIEGANG LIU \\ State Key Laboratory of Hydraulics and Mountain River Engineering, College of Water Resource \& Hydropower, \\ Sichuan University, Chengdu, 610065, China \\ liutiegang79@163.com
}

\begin{abstract}
The PRMS model was established for Zhenjiangguan watershed in the upper reach of the Minjiang River basin, China. The results showed that PRMS had an acceptable performance in simulating monthly runoff in the study area. The analysis on the impacts of precipitation changes on hydrological processes indicated that both runoff and evapotranspiration increased with the increase of precipitation. Moreover, evapotranspiration had larger sensitivity to the change of precipitation than runoff.
\end{abstract}

Key words Zhenjiangguan watershed; PRMS model; precipitation change; runoff; evapotranspiration

\section{INTRODUCTION}

The Minjiang River is the largest tributary in terms of mean runoff in the Upper Yangtze basin, and very important for the environment of the Chengdu plain (Zhang et al., 2012). Since the 1930s, however, water shortage has become a problem in the Chengdu plain. Climate is an important factor influencing hydrological conditions (Li et al., 2009). Understanding the impacts of climate change on hydrological process such as runoff and evapotranspiration (ET) in a typical watershed of this region is critical for the sound management and development of water resources. Zhenjiangguan watershed is the source area of the Minjiang River which has strategic significance for the environment, economy and social well-being of the Chengdu plain downstream (Zhang et al., 2012). In recent years, both precipitation and runoff have had decreasing trends, and climate change has obviously influenced hydrological processes in this watershed. It is necessary to study the hydrological response to climate change for this region.

A physically-based hydrologic model is useful for identifying the cause of runoff change at basin scale (Praskievicz and Chang, 2009; Chang and Jung, 2010). The US Geological Survey's (USGS) Precipitation-Runoff Modeling System (PRMS) is a hydrologic model suited for analysing the effect of climate change on runoff (Leavesley et al., 1983; Leavesley and Stannard, 1995; Leavesley et al., 2005). This model can be used to simulate the land-surface hydrologic processes of ET, runoff, infiltration, and interflow by balancing the energy and mass budgets of the plant canopy, snowpack, and soil zone on the basis of distributed climate information, and has a modular design that allows for selection of alternative hydrologic process algorithms among existing or easily added modules. However, few studies on the application of PRMS in the mountain regions in southwest of China have been reported.

This paper aims to assess the applicability of PRMS in Zhenjiangguan watershed, which is a typical watershed in the Upper Minjiang River basin in the southwest mountain region in China, and to study the impacts of precipitation change on runoff and ET at the monthly scale.

\section{METHODS}

\section{Study area}

Zhenjiangguan watershed (Fig. 1), is located in the Upper Reach of the Minjiang River, which lies between longitude $103^{\circ} 11^{\prime}-103^{\circ} 54^{\prime} \mathrm{E}$ and latitude $32^{\circ} 9^{\prime}-33^{\circ} 9^{\prime} \mathrm{N}$. The study area is about $4455 \mathrm{~km}^{2}$ and the length of main stream is about $103.7 \mathrm{~km}$. The climate is a typical alpine climate, and more than $80 \%$ of precipitation occurs from May to October. The elevation of Zhenjiangguan watershed ranges from 2500 to $5541 \mathrm{~m}$, with an average of $3871 \mathrm{~m}$. 
There are three main soils: Mollic Leptosols, Haplic Luvisols and Calcaric Cambisols, which cover $47.3 \%, 21.6 \%$ and $17.6 \%$ of the whole watershed, respectively. Grass, forest and brush are the main three land use types, and cover $64.2 \%, 28.3 \%$ and $4.9 \%$ of the study area, respectively.
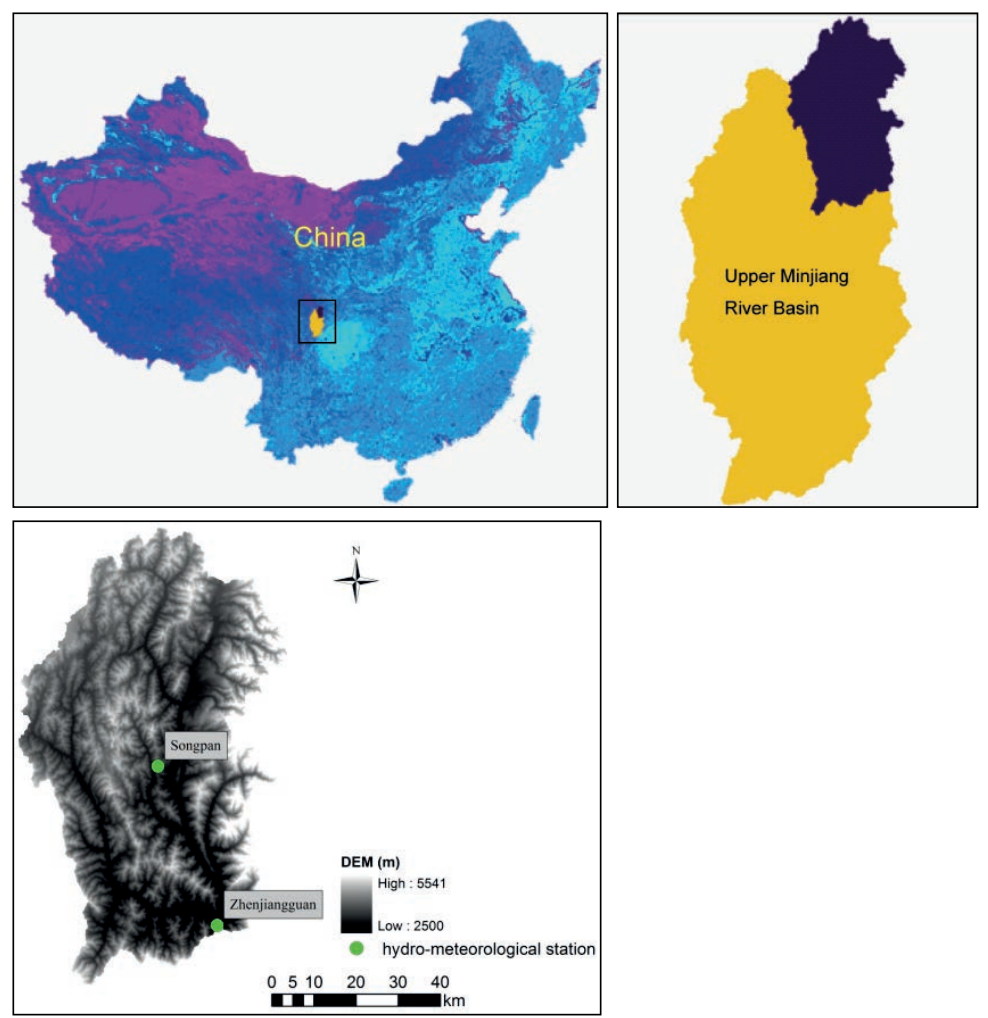

Fig. 1 Location of Zhenjiangguan watershed.

\section{Data}

Daily runoff data of Zhenjiangguan station (at the outlet of Zhenjiangguan watershed) were collected for 1984 to 1987 . Daily precipitation, daily maximum and minimum temperatures were also collected from Zhenjiangguan and Songpan stations. Potential evapotranspiration (PET) for model input was calculated by the FAO Penman-Monteith equation (Allen et al., 1998) using daily maximum and minimum temperatures, wind speed, relative humidity, and atmospheric pressure from Songpan station. The DEM (digital elevation model), soil and land use information are shown in Table 1.

Table 1 Geo-spatial data used in PRMS model.

\begin{tabular}{lll}
\hline Data & Source & Resolution \\
\hline DEM & CNIC, (http://www.cnic.cn) & $90 \mathrm{~m} \times 90 \mathrm{~m}$ \\
Land use data & Institute of Geographic Sciences and Natural Resources Research, CAS & $1: 100000$ \\
Soil data & Harmonized World Soil Database established by the Food and Agriculture & $1: 1000000$ \\
& $\begin{array}{l}\text { Organization of the United Nations (FAO) and International Institute for } \\
\text { Applied Systems Analysis (IIASA), }\end{array}$ & \\
& $\begin{array}{l}\text { (http://www.iiasa.ac.at/Research/LUC/External-World-soil- } \\
\text { database/HTML/) }\end{array}$ \\
\hline
\end{tabular}

\section{Hydrological model and input}

The PRMS model was developed to analyse the effects of climate and land-use changes on water resources. PRMS has been applied to study the impacts of climate change on water resources in different regions with a variety of climatic and physiographic characteristics (Burlando and Rosso, 2002; Dagnachew et al., 2003; Jung and Chang, 2011). 
In this study, the ArcGIS tool was used to define Hydrologic Response Units (HRUs) based on the DEM, land use and soil data of the study area (Fig. 2). There are totally 86 HRUs for the whole study area. Based on the DEM, soil and land use data, parameter information required by PRMS was prepared for each HRU according to the required format, such as area (hru area), average elevation (hru_elev), average slope (hru_slope), hru major vegetation types (cove-type), and so on.

\section{Calibration and validation}

Monthly runoff was used to calibrate manually the PRMS model set up for Zhenjiangguan watershed for the period 1984-1986, and to validate the model for 1987. The performance of PRMS model was assessed by using the coefficient of determination $\left(\mathrm{R}^{2}\right)$, relative error (RE) and Nash-Sutcliffe (NS) efficiency coefficient (Nash and Sutcliffe, 1970). The parameters of PRMS model selected for calibration and validation include smidx_coef, hru percent_imperv, smidx_exp, and carea_max. The part calibrated parameters and their descriptions are shown in Table 2.

Table 2 Part calibrated parameters and their description.

\begin{tabular}{|c|c|c|}
\hline Parameter & Description & Calibrated value \\
\hline smidx_coef & Coefficient in non-linear contributing area algorithm & 0.2 \\
\hline hru_percent_imperv & Decimal fraction of HRU area that is impervious & 0.03 \\
\hline gwflow_coef & Linear coefficient to route water in ground-water & 0.015 \\
\hline smidx_exp & Exponent in non-linear contributing area algorithm & 0.3 \\
\hline carea_max & $\begin{array}{l}\text { Maximum possible area contributing surface runoff, expressed as } \\
\text { decimal fraction of HRU area }\end{array}$ & 0.4 \\
\hline
\end{tabular}

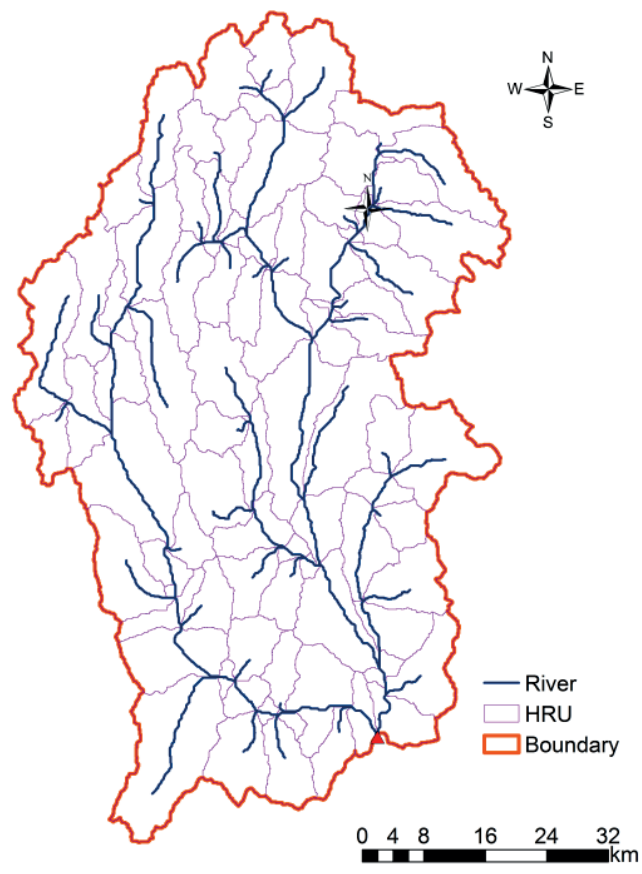

Fig. 2 Hydrologic response units (HRUs) of Zhenjiangguan watershed.

\section{RESULTS AND DISCUSSION}

\section{Calibrated and validated results}

Monthly runoff at Zhenjiangguan station from 1984 to 1986 was used to calibrate the parameters of PRMS, and that from 1987 was used for validation. Figures 3 and 4 show the comparison of the simulated and observed runoff in the calibration and validation periods. The simulated values 
generally had good agreements with the observed values at the monthly scale for the two periods. Note that there were relatively larger errors in the period from April to June for each year, which might result from the inaccuracy of the part calibrated parameters.

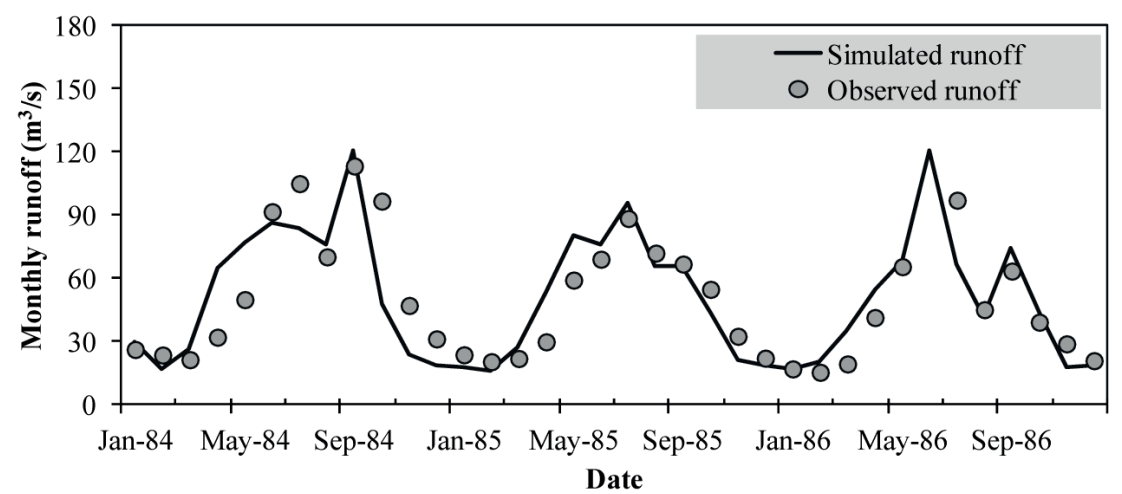

Fig. 3 Comparison of simulated and observed runoff for calibration period.

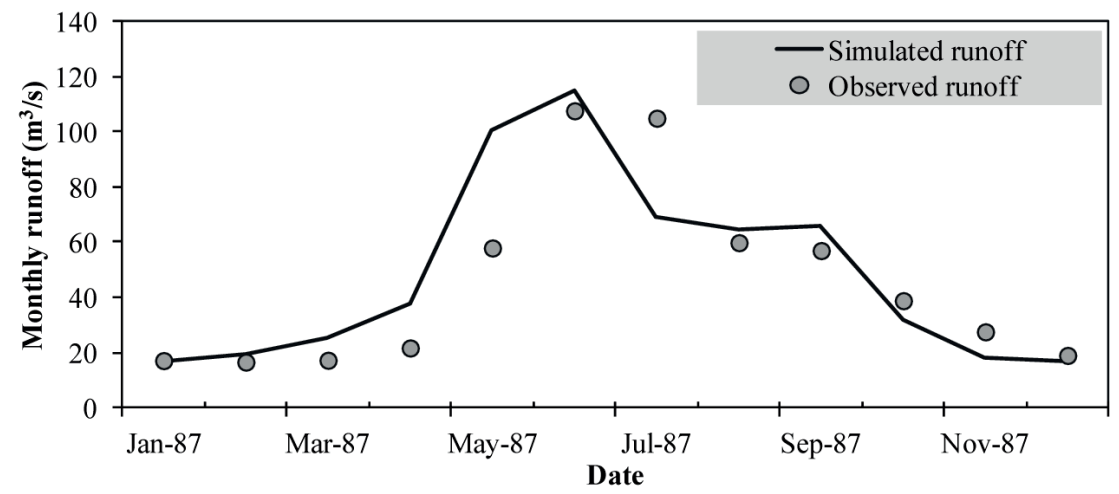

Fig. 4 Comparison of simulated and observed runoff for validation period.

The statistics also show that the model had a good performance (Table 3), although the model overestimated runoff for both the calibration and validation periods. As $\mathrm{R}^{2}$ and NS were both larger than 0.70 , and RE were less than $10 \%$, we think that the performance of the model is acceptable.

Table 3 Statistics of model calibration and validation.

\begin{tabular}{llll}
\hline Period & $\mathrm{R}^{2}$ & $\mathrm{RE}$ & $\mathrm{NS}$ \\
\hline Calibration & 0.75 & $2.7 \%$ & 0.75 \\
Validation & 0.73 & $6.2 \%$ & 0.70 \\
\hline
\end{tabular}

\section{Impact of precipitation change on runoff and ET}

Two precipitation change scenarios were set up, increasing and decreasing by $20 \%$ the observed daily precipitation from 1984 to 1987 . Figure 5 shows the comparison of the observed and simulated runoff for these two scenarios. The results indicated that runoff increased with the increase of the precipitation. Accordingly, ET also increased when precipitation increased. It can be seen from Table 4 that ET was more sensitive to the change of precipitation than runoff. When precipitation change increased from $-20 \%$ to $20 \%$, runoff change increased from $-15.8 \%$ to $11.2 \%$, while ET change ranged from $-20.5 \%$ to $20.8 \%$. 
Table 4 Changes of Runoff and ET for precipitation scenarios.

\begin{tabular}{llll}
\hline Items & \multicolumn{3}{l}{ Precipitation change } \\
\cline { 2 - 4 } & $+20 \%$ & $\pm 0 \%$ & $-20 \%$ \\
\hline Runoff change & $11.2 \%$ & $0.0 \%$ & $-15.8 \%$ \\
ET change & $20.8 \%$ & $0.0 \%$ & $-20.5 \%$ \\
\hline
\end{tabular}

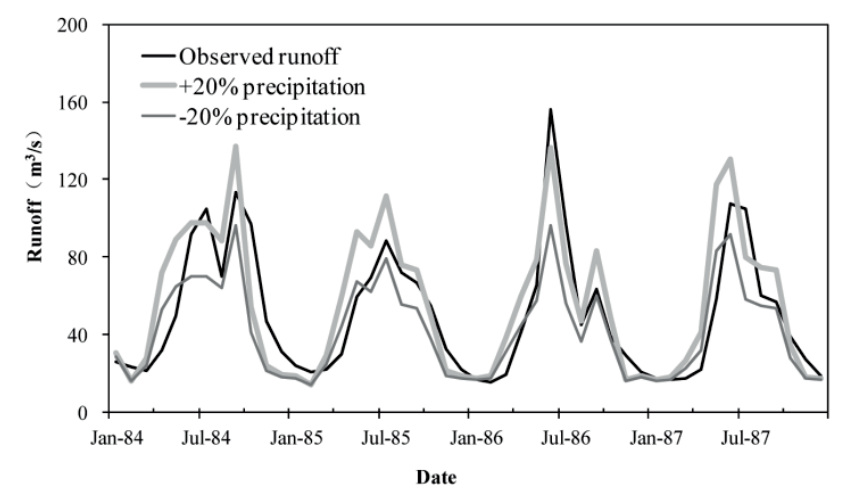

Fig. 5 Observed and simulated runoff curves.

\section{CONCLUSION}

In this study, the PRMS model was established for Zhenjiangguan watershed in the Upper Minjiang River. The assessment of calibration and validation indicated that the performance of the model was acceptable in the study area. However, the lack of weather and runoff stations had a negative influence on the quality of the simulation. Despite these limitations, the model generally reflected the variation of runoff in the calibration and validation periods.

Based on the established PRMS model, the impacts of precipitation change on runoff and ET were discussed preliminarily. Both runoff and ET increase with precipitation, and ET has a larger sensitivity for the change of precipitation. This study demonstrated that PRMS was suitable for runoff simulation and could be used to analyse the impact of climate change on hydrological processes in the typical mountain river basin in southwest China. It is recommended to collect the weather and runoff data of more stations for further validation and evaluations of PRMS in the study area, and use of more complex climate change scenarios, such as General Circulation Models (GCMs) for future studies.

Acknowledgements This research was supported by the National Natural Science Foundation of China (No. 41301021).

\section{REFERENCES}

Allen, R.G., et al. (1998) Crop Evapotranspiration. Guidelines for computing crop water requirements. FAO, Rome, FAO Irrig. Drain. Paper 56.

Burlando, P. and Rosso, R. (2002) Effects of transient climate change on basin hydrology. 1. Precipitation scenarios for the Arno River, central Italy, Hydrological Processes 16, 1151-1175.

Chang, H. and Jung, I.W. (2010) Spatial and temporal changes in runoff caused by climate change in a complex large river basin in Oregon. Journal of Hydrology 388, 186-207.

Dagnachew, L., et al. (2003) Hydrological response of a catchment to climate and land use changes in tropical Africa: case study South Central Ethiopia. Journal of Hydrology 275, 67-85.

Jung, I. and Chang, H. (2011) Assessment of future runoff trends under multiple climate change scenarios in the Willamette River Basin, Oregon, USA. Hydrological Processes 25, 258-277.

Leavesley, G.H., et al. (1983) Precipitation-runoff modeling system: User's Manual. Water-Resources Investigations 83-4238, Denver, CO.

Leavesley, G.H., et al. (2005) USGS modular modelling system (MMS)-precipitation-runoff modeling system (PRMS) MMSPRMS, In: Singh, V., Frevert, D. (eds) Watershed Models. CRC Press, Boca Raton, FL.

Leavesley, G.H. and Stannard, L.G. (1995) The precipitation-runoff modeling system—PRMS. In: Singh, V.P. (ed.), Computer Models of Watershed Hydrology, Water Resources Publications. 
Li, Z., et al. (2009) Impacts of land use change and climate variability on hydrology in an agricultural catchment on the Loess Plateau of China. Journal of Hydrology 377, 35-42.

Nash, J.E. and Sutcliffe, J.V. (1970) River flow forecasting through conceptual models. Part I. A discussion of principles Journal of Hydrology 10, 282-290.

Praskievicz, S. and Chang, H. (2009) A review of hydrologic modeling of basin-scale climate change and urban development impacts. Progress in Physical Geography 33, 650-671.

Zhang, M.F., et al. (2012) The effect of forest harvesting and climatic variability on runoff in a large watershed: The case study in the Upper Minjiang River of Yangtze River basin. Journal of Hydrology 464-465, 1-11. 